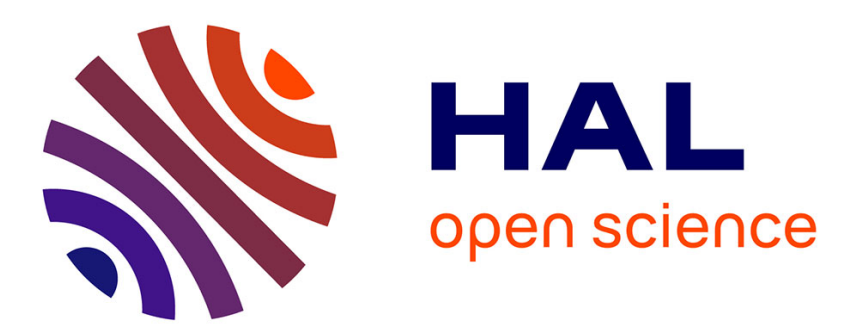

\title{
Adiabatic Shear Fracture of Titanium Alloy Subjected to High Strain Rate and high Temperature Loadings \\ W. Lee, C. Lin
}

\section{To cite this version:}

W. Lee, C. Lin. Adiabatic Shear Fracture of Titanium Alloy Subjected to High Strain Rate and high Temperature Loadings. Journal de Physique IV Proceedings, 1997, 07 (C3), pp.C3-855-C3-860. 10.1051/jp4:19973144 . jpa-00255432

\section{HAL Id: jpa-00255432 https://hal.science/jpa-00255432}

Submitted on 1 Jan 1997

HAL is a multi-disciplinary open access archive for the deposit and dissemination of scientific research documents, whether they are published or not. The documents may come from teaching and research institutions in France or abroad, or from public or private research centers.
L'archive ouverte pluridisciplinaire HAL, est destinée au dépôt et à la diffusion de documents scientifiques de niveau recherche, publiés ou non, émanant des établissements d'enseignement et de recherche français ou étrangers, des laboratoires publics ou privés. 


\title{
Adiabatic Shear Fracture of Titanium Alloy Subjected to High Strain Rate and high Temperature Loadings
}

\author{
W.S. Lee, C.F. Lin
}

Department of Mechanical Engineering, National Cheng Kung University, Tainan 70101, Taiwan, ROC

\begin{abstract}
The aims of this study are to realize under which conditions adiabatic shearing occurs, and to better understand the formation and variations of the adiabatic shear band of Ti-6Al-4V alloy subjected to high strain rate and high temperature conditions with microstructural observation. The cylindrical specimens are first deformed at strain rate ranging from $5 \times 10^{2}$ to $3 \times 10^{3} \mathrm{~s}^{-1}$ under initial deformation temperature of $700^{\circ} \mathrm{C}, 900^{\circ} \mathrm{C}$ and $1100^{\circ} \mathrm{C}$, respectively, by means of compressive split-Hopkinson bars, then, the fracture phenomenon and morphology of the adiabatic shear bands are examined and analyzed with the optical microscopy and scanning electron microscopy. The results of these experiments and how adiabatic shearing behaviour correlates with the effect of strain rate and temperature are discussed.
\end{abstract}

\begin{abstract}
Résumé. Cette étude a pour objectif d'une part de déterminer les conditons pour lesquelles les bandes de cisaillement adiabatiques se produisent dans l'alliage de titane et d'autre part de mieux comprendre, grâce aux observations microscopiques, le mode de formation et la variation des bandes de cisaillement adiabatique lorsque cet alliage est soumis aux grandes vitesses de déformation et aux températures élevées. Les échantillons ont été déformés dans une gamme de vitesses de déformation allant de $5 \times 10^{2}$ à $3 \times 10^{3} \mathrm{~s}^{-1}$ et aux températures de $700^{\circ} \mathrm{C}$. $900^{\circ} \mathrm{C}$ et $1100^{\circ} \mathrm{C}$ à l'aide d'un dispositif de barres d'Hopkinson. Le phénomène de rupture et la forme des bandes de cisaillement adiabatique ont été examinés et analysés en microscopie optique et électronique en balayage. On discute les résultats de ces essais et la corrélation des effets de la vitesse de déformation et de la température sur le comprotement de cisaillement adiabatique.
\end{abstract}

\section{INTRODUCTION}

Adiabatic shear banding, a localized plastic instability phenomenon resulted from dynamic impact and high speed loading, has been identified as one of the major fracture modes in high rate deformation of metals. It leads to formation of certain zones of intense localized shear deformation which can act as the sites for the initiation and growth of voids and cracks. In the limit, the material may fail completely along the paths defined by the precursor shear bands.

The adiabatic shear phenomenon is first recognized by Trent in 1941 [1] and observed by Zener and Hollomon in 1944 [2]. Since then, a number of researches on this subject have been conducted in a variety of metals, and their results have been published in the literature [3-5]. Also, some researchers have interpreted adiabatic shear theoretically in several ways [6-8]. Roger [9] has classified the bands into "deformed" and "transformed" types. The former is a very thin zone of deformation associated with a very high shear strain, while the latter a crystallographic phase change occurs.

It has been reported that the titanium alloys have an excellent combination of strength and ductility $[10,11]$, but it is very easy to form the isolated voids and arrays of rounded cavities within the shear bands. Some investigators attempted to find out a relationship between the formation of the band and the work hardening exponent, density, specific heat, heat diffusivity, flow stress and strains [12-14]. However, the study of adiabatic shearing formed in titanium alloy under both high temperature and high strain rate conditions is scantly. In fact, the shear band failure mechanism is still not completely understood, especially its relationship with high rate and high temperature loading deformation. Therefore, in this study, the shear band phenomena of $\mathrm{Ti}-6 \mathrm{Al}-4 \mathrm{~V}$ alloy under high temperature and high strain rate loading conditions are studied. The flow behaviour, variations of microstructure, and fracture mode induced by adiabatic shearing are also described. 


\section{EXPERIMENTAL PROCEDURE}

Hot-extruded commercial Ti-6Al-4V bars $(6.1 \mathrm{Al}, 4.0 \mathrm{~V}, 0.2 \mathrm{Fe}, 0.15 \mathrm{O}, 0.008 \mathrm{~N}, 0.014 \mathrm{C}$ and the resl Til of $12.7 \mathrm{~mm}$ diameter, purchased from $\mathrm{B} \& \mathrm{~S}$ aircraft alloys Inc., USA, are used in this investigation. The initial microstructure is in $\alpha+\beta$ phase. Cylindrical specimens, $10 \mathrm{~mm}$ in diameter and $10 \mathrm{~mm}$ in length. are machined from the extruded bar. Dynamic compression tests are performed using compressive splitHopkinson bar at three different temperatures, $700^{\circ} \mathrm{C}, 900^{\circ} \mathrm{C}$ and $1100^{\circ} \mathrm{C}$, under strain rate ranging from $5 \times 10^{2}$ to $3 \times 10^{3} \mathrm{~s}^{-1}$. In order to realize the temperature effect on the flow characteristics, room temperature tests are also performed to find out the basic mechanical properties. The details of the experimental setup, test methods and data acquisition are reported in [15]. After compression, the cross section of the deformed specimens is ground, polished and etched in the solution of $2 \% \mathrm{HF}, 10 \% \mathrm{HNO}$, and $88 \% \mathrm{H}_{2} \mathrm{O}$ for $10 \mathrm{~min}$ in order to observe the aspects of adiabatic shear bands by means of $\mathrm{MeF}_{3}$ optical microscopy. Fracture features are examined with a JEOL JXA-840 scanning electron microscope operating at an acceleration potential of $20 \mathrm{KV}$. The microhardness of adiabatic shear band and matrix are measured with a Matsuzawa MXT 70 microhardness tester with a $50 \mathrm{~g}$ load.

\section{RESULTS AND DISCUSSION}

\subsection{Flow Stress-Strain Behaviour}

Typical true stress-strain curves for specimens deformed at room temperature and the said three high temperatures under different strain rates are shown in Figs. 1 and 2 respectively. It is noticeable that material's strength is sensitive to both strain rate and temperature. For all tested temperatures, the flow stress increases with strain, however, at any specific strain rate, the magnitude of flow stress decreases considerably as the temperature increases. This suggests that the effect of temperature on the flow stress in more pronounced than that of strain rate. In addition, the stress-strain curves also show that the rate of work hardening decreases rapidly with the temperature. This decrease in rate of work hardening demonstrates that, in high temperature region, the thermal softening process dominates the flow behaviour of the material, and that, on the microscale, the annihilation of dislocations induced due to the rise of temperature occurs more rapidly than the generation caused by the strain rate effect.

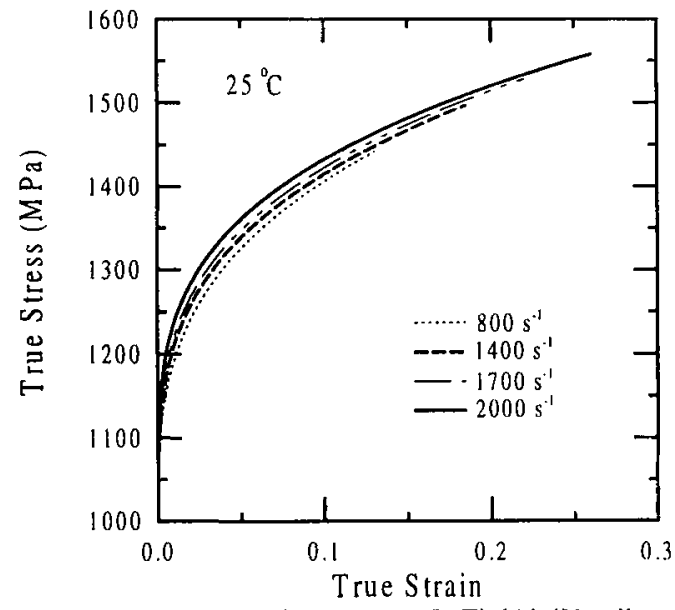

Figure 1: True stress-strain curve of Ti-6Al-4V alloy deformed at $25^{\circ} \mathrm{C}$ under different strain rates.

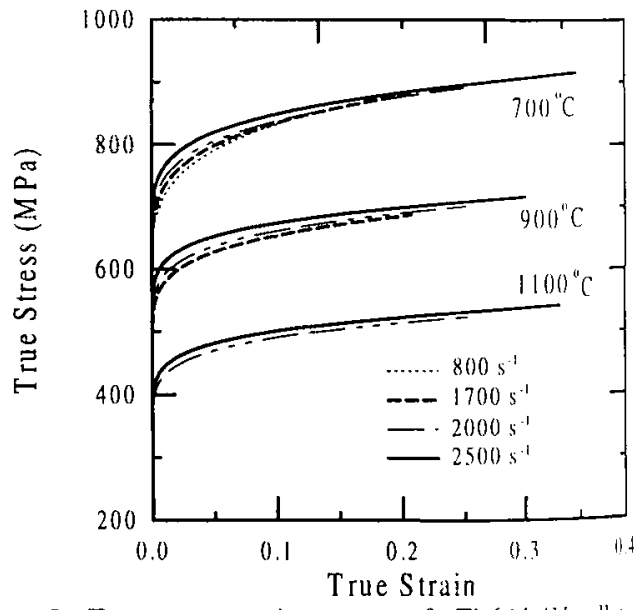

Figure 2: True stress-strain curve of Ti-6Al-4V :alliw: deformed at $700^{\circ} \mathrm{C}, 900^{\circ} \mathrm{C}$ and $11000^{\circ} \mathrm{C}$ under different strain rates. 


\subsection{Fracture Behaviour}

The fracture aspects of deform specimens obtained from different test conditions are examined by means of optical and scanning electron microscope. Our observations found that the fracture occurs at strain rate higher than $2 \times 10^{3} \mathrm{~s}^{-1}$ under three high tested temperatures of $700^{\circ} \mathrm{C}, 900^{\circ} \mathrm{C}$ and $1100^{\circ} \mathrm{C}$, and that it is accompanied with adiabatic shear bands. The conditions for occurrence of shear bands and fracture are summarized in Fig. 3. It is obvious that the temperature and strain rate not only exhibit a strong effect on fracture behaviour but also play a key role to determine whether shear band will occur or not. Figs. 4 and 5 show optical micrographs of the fracture features of specimens deformed at $2 \times 10^{3} \mathrm{~s}^{-1}$ and at $700^{\circ} \mathrm{C}$. The transformed adiabatic shear bands can be clearly identified as they run across the specimen. When the critical loading is attained, the adiabatic shear band forms initially at the end surface of the specimen near one periphery, see Fig. 4, and then propagates in two directions with two different velocities. The faster one run diagonally through the depth of the specimen to the opposite periphery with an angle of $45^{\circ}$ to the compression axis, Fig. 5, while the slow one grows laterally like an arc on the cross section, Fig. 4.

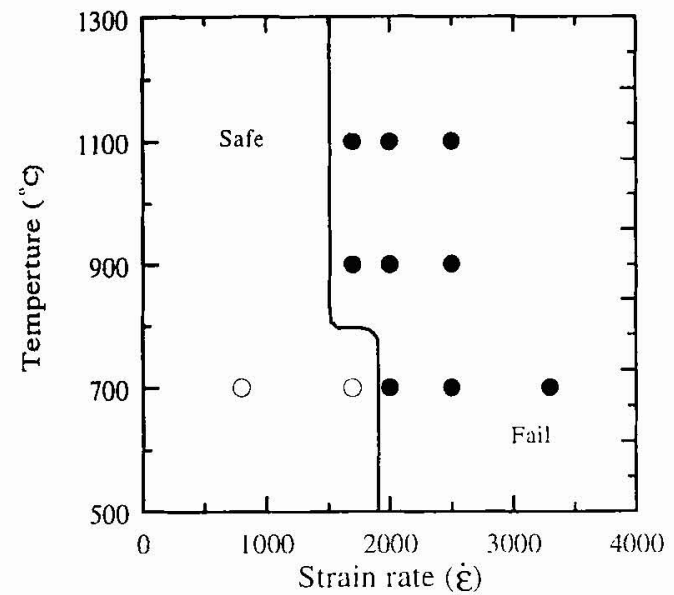

Figure 3: Workability map for occurrence of shear bands is Ti-6Ai-4V alloy

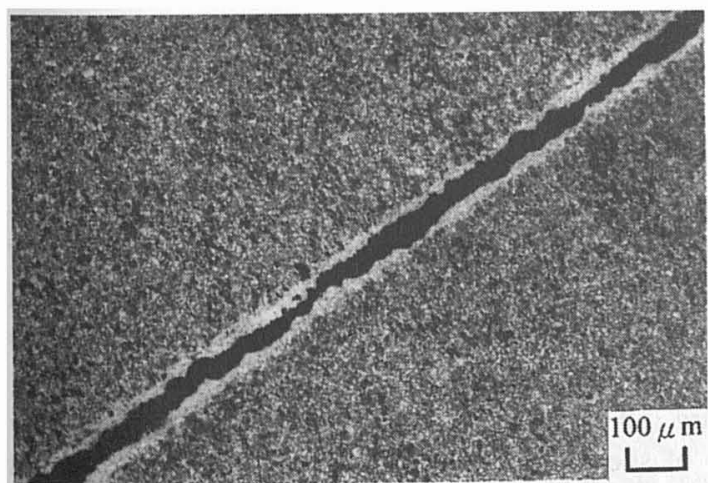

Figure 5: The side view of fracture feature for specimen deformed at $700^{\circ} \mathrm{C}$ under strain rate of $2 \times 10^{3} \mathrm{~s}^{-1}$

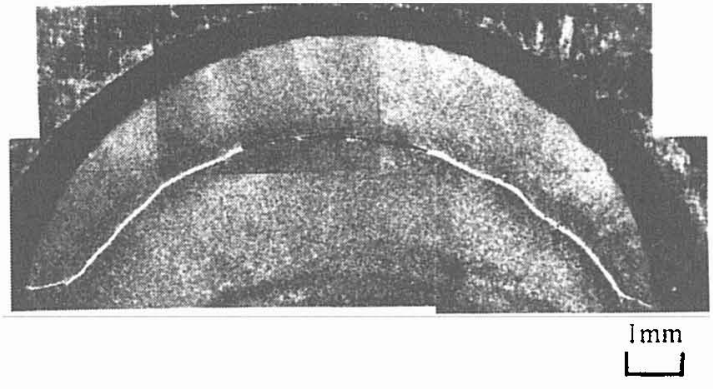

Figure 4: The top view of fracture feature for specimen deformed at $700^{\circ} \mathrm{C}$ under strain rate of $2 \times 10^{3} \mathrm{~s}^{-1}$

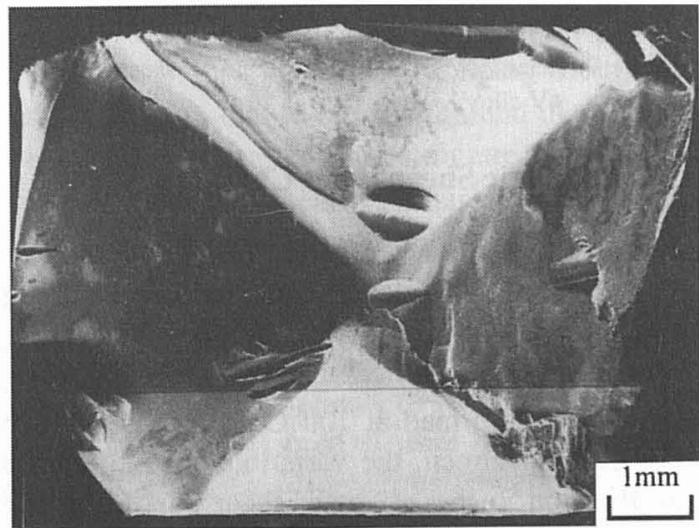

Figure (o: Fracture surface observed along the shear band, showing a form of X's. 
In fact, under uniaxial compression loading, the deformation of specimen is initial homogeneous without any radial and hoop stress. However, when the plasticity instability occurs, the deformation is localized in a narrow area and results in an unstable flow passing along the direction of maximum shear stress, i.e. $45^{\circ}$ to the compression axis. On the other hand, with further progress of axial strain, the specimen bulges and a hoop stress appears at the equatorial plane of the cylindrical surface, which induce a tensile stress state on the specimen. Hence, during dynamic compression, the maximum shear stress combined with tensile stress are applied in the specimen and lead an intense deformation region in the form of X's on the separated fracture surface, Fig. 6.

It is generally agreed that adiabatic shear bands are the site where fracture and nucleation of crack used to occur, and that no unique feature of the fracture of adiabatic shear band is found because of the influence of the stress condition and cooling rate. Fig. 7 shows a relatively smooth feature of fracture surface produced along adiabatic shear band. As can be expected, the cleavage facets predominate on the fracture surface, corresponding to a brittle fracture mode. The striations parallel to the shear direction are also seen. Actually, after the onset of the instability, a dramatic rise of temperature in the band causes melt and solidification first, and then contraction of the solidified material produces cracks. The rapid cooling of the material in the band also makes the material very brittle and contributes to its fracture. $B$ : combining above fracture phenomena, a schema of the fracture feature and the orientation of adiabalic shear band is shown in Fig. 8, which can be used to describe the fracture mechanisms of Ti-6Al-4V alloy.

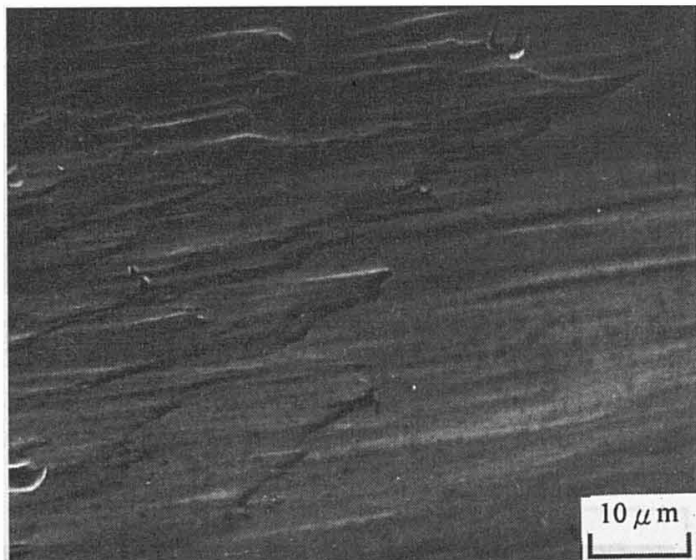

Figure 7: Relatively smooth shear band surface of Ti-6Al$4 \mathrm{~V}$ alloy.

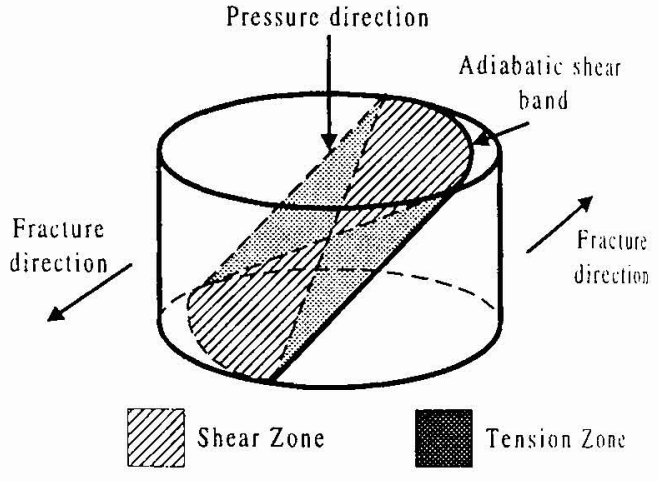

Figure 8: The schematic description of the fracture feature and the orientation of adiabatic shear band.

\subsection{Adiabatic Shear Band Characteristics}

The above mentioned fracture behaviour shows that adiabatic shearing is an important failure mode for Ti-6Al-4V alloy loaded at high strain rate and high temperature conditions. In order to study the effect of temperature and strain rate on the characteristics of adiabatic shear bands in detail, the deformed specimens are polished and examined by optical microscopy. Figs. 9-11 show the features for the specimens deformed at $700^{\circ} \mathrm{C}, 900^{\circ} \mathrm{C}$ and $1100^{\circ} \mathrm{C}$ respectively under a fixed strain rate of $2 \times 10^{3} \mathrm{~s}^{-1}$. For each specimen, the variations in the microstructure indicate a phase change and an extensive flow: localization in the adiabatic shear band. The features of shear band also imply that the nucleation and growth of shear band are influenced significantly by the original microstructure and initial hardness of matrix material. 


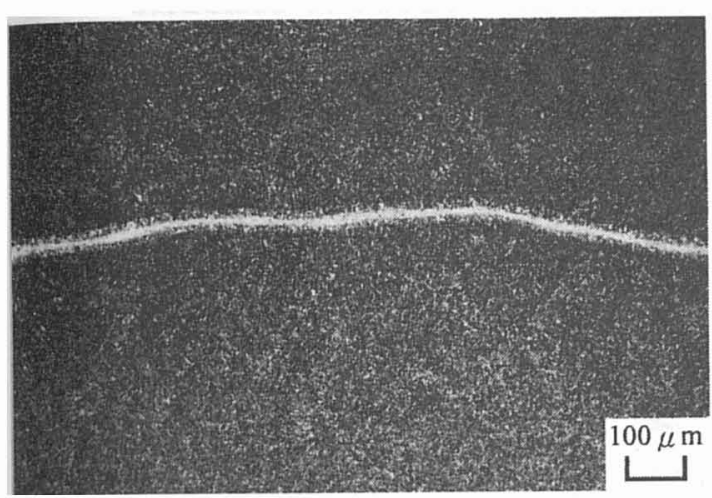

Figure 9: The feature of the adiabatic shear band obtained from the specinien lested at $7000^{\circ} \mathrm{C}$ under $2 \times 10^{3} \mathrm{~s}^{-1}$

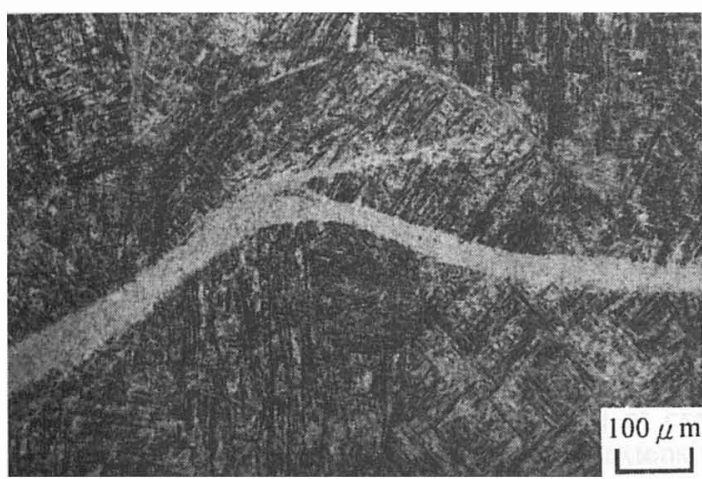

Figure 11: The feature of the adiabatic shear band obtained from the specimen tested at $1100^{\circ} \mathrm{C}$ under $2 \times 10^{3} \mathrm{~s}^{-1}$.

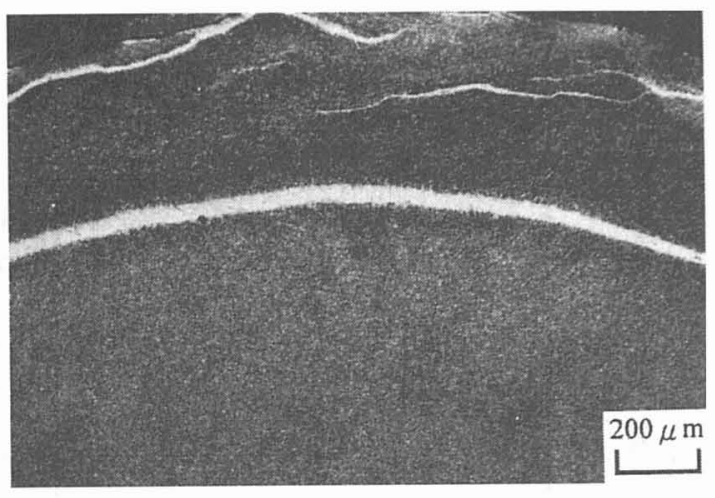

Figure 10: The feature of the adiabatic shear band obtained from the specimen tested at $900^{\circ} \mathrm{C}$ under $2 \times 10^{3} \mathrm{~s}^{-1}$

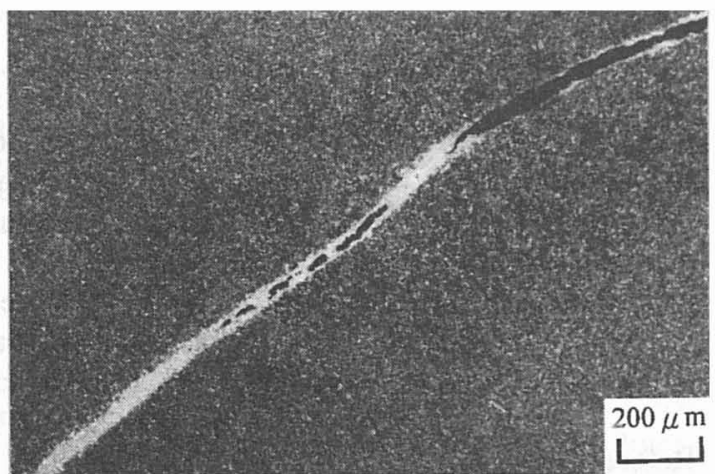

Figure 12: Adiabatic shear band and an associated crack in Ti-6Al4V alloy deformed at $900^{\circ} \mathrm{C}$ under $2.5 \times 10^{3} \mathrm{~s}^{-1}$

It is also interesting to note that there are some secondary shear bands propagating along the periphery zone of specimen for specimen deformed at $900^{\circ} \mathrm{C}$, Fig. 10 , due to the friction and increase of temperature. If we compare the Figs. 9 and 10 with Fig.11, a change of matrix microstructure from $\alpha+\beta$ phase to a single phase of $\beta$ is observed. Besides, the cracks within the shear bands are formed at late stages of deformation. A sharp crack tip, Fig. 12, extending along the transformed band indicates that the brittle transformed bands are responsible for microcracks.

Based on the microstructural observations, the thickness and microhardness of adiabatic shear band varying with temperature are measured quantitatively. Fig. 13 clearly shows that the thickness of shear band increases with temperature under a linear relationship, while Fig. 14 shows the microhardness of shear band. It is obviously that the maximum microhardness in the central zone of shear band decreases with an increase of temperature. Also, compared with matrix hardness, the different augmentation rates of microhardness in shear band indicate again that the properties of the shear band are dependent on those of the matrix. 


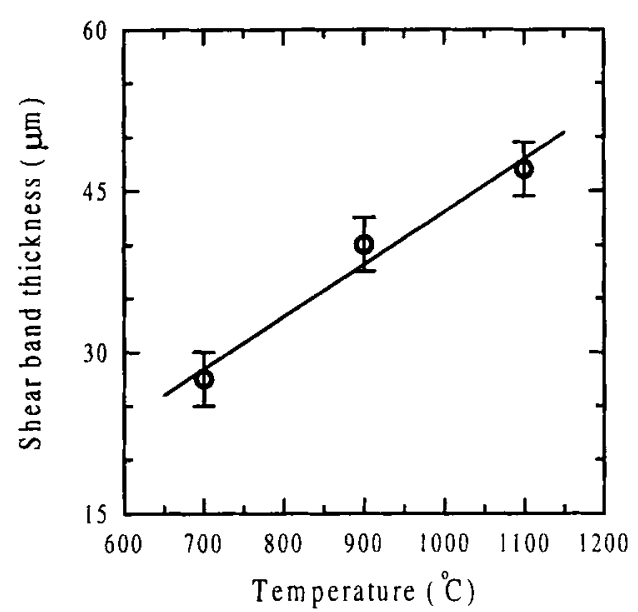

Figure 13: Variations of thickness of adiabatic shear band as a function of temperature

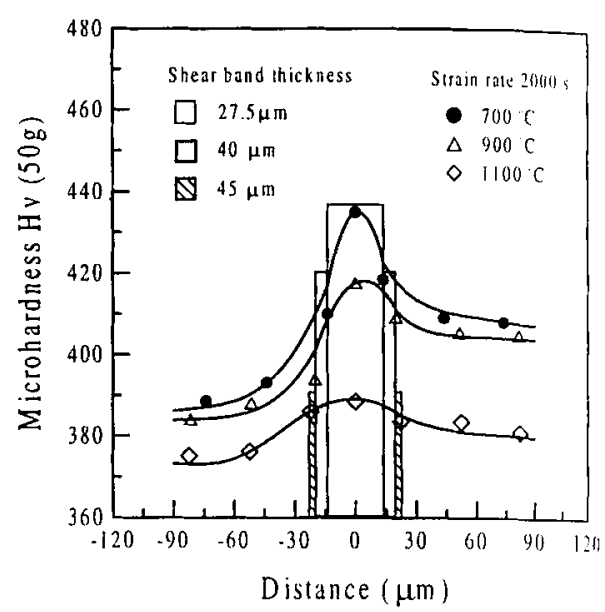

Figure 14: Changes of microhardness of adiabatic shear band for specimen deformed at different temperatures.

\section{CONCLUSIONS}

Our results show that the formation of "transformed" shear band of the Ti-6Al-4V alloy is very" susceptible to high strain rate and high temperature loading and that the adiabatic shear band is a precursor to both crack formation and fracture in high temperature range. Microstructural analyses reveal that the features of adiabatic shear band and their final thickness and microhardness depend strongly on both the strain rate and temperature. All these experimental results allow us to predict the optimum conditions to resist flow localization and shear band formation under high velocity hot metal working processes.

\section{References}

[1] Stelly M., Legrand J. and Dormeval R. In Shock Waves and High Strain Rate Phenomena in Metals. Eds M. A. Meyers and L. E. Murr, Plenum Press, New York, 1981 pp. 113-122.

[2] Zener C., Holloman J. H., J. Appl. Phys. 15 (1944) pp. 22-31.

[3] Newcomb S. B., Stobbs W. M., Mater. Sci. Enging. 66 (1984) pp. 185-201.

[4] Dodd B., Bai Y., Mater. Sci. Technol. 1 (1985) pp. 38-44.

[5] Timothy S. P., Acta metall. 35 (1987) pp. 301-306

[6] Semiatin S. L., Staber M. R., and Jonas, J. J., Acta metall. 32 (1984) pp. 1347-1356.

[7] Wu F. H., Freund L. B., J. Mech. Phys. Solids 32 (1984) pp. 119-127.

[8] Clifton R. J., Duffy J., Hartley K. H., and Shawki T. G., Scripta metall. 18 (1984) pp. 443-452.

[9] Rogers H. C., Ann. Rev. Matls Sci. 9 (1979) pp. 283-292.

[10] Wood R. A., Titanium Alloy Handbook, Metals and Ceramics Information Center, Batlelle, Publication No. MICI-HB-02, December 1972.

[11] Matthew J. D. Jr., Titanium: A Technical Guide, Am. Soc. Metals, Metals Park, OH 44073, 1989.

[12] Timothy S. P., Acta Metall. 35 (1987) pp. 301-309.

[13] Bedford A. J., Wingrove A. L., and Thompson K. R. L., J. Aust. Inst. Metals 19 (1974) pp. 61 -68.

[14] Semiatin S. L., Lahoti G. D., Metall. Trans. 12A (1981) pp. 1705-1712.

[15] Lee W. S., Lam H. F., J. of Mater. Proc. Tech., 57 (1996) pp. 233-240. 